\title{
Recycled aggregates in concrete production: engineering properties and environmental impact
}

\author{
Mohammed Seddik Meddah* \\ Department of Civil \& Architectural Engineering, Sultan Qaboos University, 123 Al-Khod, Oman
}

\begin{abstract}
Recycled concrete aggregate is considered as the most abundant and used secondary aggregate in concrete production, other types of solid waste are also being used in concrete for specific purposes and to achieve some desired properties. Recycled aggregates and particularly, recycled concrete aggregate substantially affect the properties and mix design of concrete both at fresh and hardened states since it is known by high porosity due to the adhered layer of old mortar on the aggregate which results in a high water absorption of the recycled secondary aggregate. This leads to lower density and strength, and other durability related properties. The use of most recycled aggregate in concrete structures is still limited to low strength and non-structural applications due to important drop in strength and durability performances generated. Embedding recycled aggregates in concrete is now a current practice in many countries to enhance sustainability of concrete industry and reduce its environmental impacts. The present paper discusses the various possible recycled aggregates used in concrete production, their effect on both fresh and hardened properties as well as durability performances. The economic and environmental impacts of partially or fully substituting natural aggregates by secondary recycled aggregates are also discussed.
\end{abstract}

\section{Introduction}

Both natural and processed resources and energy are one of the most fundamental elements for the daily life of humankind. The tremendous and continuous development of modern societies has been accompanied by a fast and extensive use of natural resources that are considered as the locomotive of such social and economic growing. All humankind activities including industrial ones need the utilization of energy and large variety of natural resources.

Construction industry is considered as the engine of the economy and one of the main industrial activities. It is known to be the largest consumed of natural resources and one of the principal consumed of energy. The rapid and impressive human development during the last and current century, especially after the end of the second World War has led to a huge need of new buildings and infrastructures. The massive destruction induced by the WWII, especially in Europe has led to an extensive and abusive use of natural and non-renewable resources to not only rebuild and repair the destroyed infrastructures but also the huge need for new infrastructures. Moreover, the global population is in continuous increase, which increases demand for new housing and other related infrastructures.

In recent years, it has been recognized that increasing energy consumption from all sources could even contribute to the global climate change both directly and indirectly. It is anticipated that global warming phenomena will cause extremely serious problems in the future and should be addressed as early as possible. Not only the global climate change but also another very serious problem facing the modern society growing is the depletion of non-renewable resources due to their extensive use. The Statistical Review of World Energy released by British Petroleum indicated that the confirmed reserves-to-production ratio of oil, natural gas and coal are 53, 55 and 113 years respectively [1].

Although the direct greenhouse gases $\mathrm{CO} 2, \mathrm{CH} 4$, and $\mathrm{N} 2 \mathrm{O}$ are naturally occurring in the atmosphere, intensive human activities have increased their atmospheric concentrations. It has been estimated that from the preindustrial era (i.e., ending about 1750) to 2013, concentrations of these major greenhouse gases have increased globally by 43,152 , and $20 \%$, respectively $[2,3]$. It is generally agreed that current and most often used construction materials as well as building methods are unsustainable, having large environmental impacts such as $\mathrm{CO}_{2}$ emissions, energy consumption, pollution, dusts, depletion of natural resources, generating considerable amount of solid waste. Among all existing construction materials, concrete is most used material because of many technical and economic factors. Concrete is also the second largest consumed material on earth just after water.

All countries are concerned by the global climate changes and greenhouse gas emissions including the developing countries and emerging economy such as Indonesia which contributes by around $1.9 \%$ of the

*Corresponding author: seddikm@squ.edu.om 
global $\mathrm{CO}_{2}$ emissions as per data published in 2011 (Fig.1) [4].

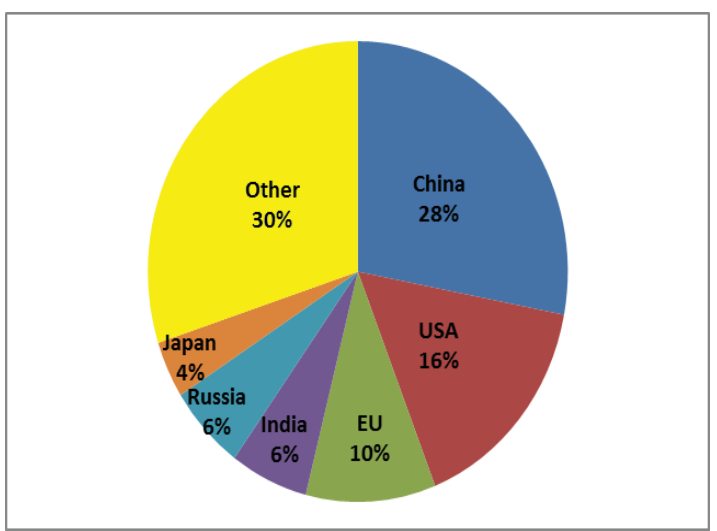

Fig.1. Breakdown of Total World Greenhouse Gas Emissions: 2015 [4]

Sustainable development was introduced to overcome those issues related to extensive use of energy and natural resources. It has been defined as "development that meets the need of actual generation without compromising the need of future generation. In other words, sustainable development is a development that will satisfy the need of people without neither depleting natural resources and energy, nor cause serious environmental impacts.

To address the issue of sustainability and assess its level, it is essential to define certain indexes that could be used to evaluate human activity in regards to sustainability concept. In construction industry, a sector that consumes a large part of natural resources, assessing sustainability is still a subjective matter.

Construction industry sector is intended to build various types of infrastructures that form the basis for social and economic activities of mankind. Over the years, infrastructures are built using mainly three principal materials: concrete, metal/steel and timber in addition to glass which becomes one of the main materials used in contemporary construction. As the world population is in continuous growing, demand for new housing and infrastructures is increasing annually. The amount of construction materials produced annually is also in incessant raise. According to the United States Geological Survey Report [5], the world total cement production has reached 4.193 billion tons in 2015 while CEMBUREAU [6] has estimated the total world cement production by 4.6 billion tons. While cement is not used only for making concrete but it is used also for other purposes, the concrete production was estimated to be around 32 billion tons based on an average of $300 \mathrm{~kg}$ of cement for $1 \mathrm{~m}^{3}$ of concrete.

The production of steel was estimated to approximately 1.5 billion tons with about half of this is likely to be used in construction. As for wood, its production is estimated for approximately 3.5 billion $\mathrm{m}^{2}$ with less than $50 \%$ of which is believed to be used in construction related purposes [7]. Except that the use of wood is very common as an interior material for housing, office buildings and others. These data show that concrete is the most used construction materials far exceeding in terms of the amount produced and consumed compared to the two other major construction materials steel and wood. Thought what made this possible for concrete to be the most used construction materials is mainly attributable to the fact that concrete as a whole, is made based on rocks and minerals that are mostly abundant and available in sufficient quantity everywhere.

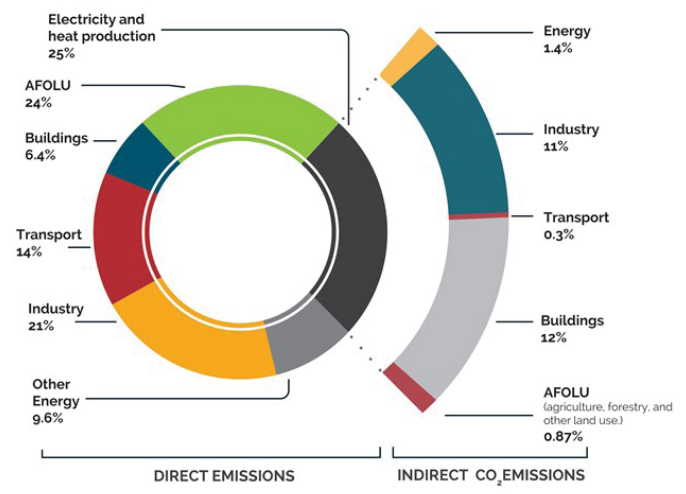

Fig.2. Direct and indirect $\mathrm{CO}_{2}$ emissions per sector in 2010 [2]

Table 1. World steel/cement production [7]

\begin{tabular}{|l|l|l|l|l|}
\hline Country & $\begin{array}{l}\text { Crude } \\
\text { steel } \\
\text { Production } \\
\text { (Million } \\
\text { metric } \\
\text { tons) } \\
(\mathbf{2 0 1 5})\end{array}$ & $\begin{array}{l}\text { \% } \\
\text { Share } \\
\text { of } \\
\text { total }\end{array}$ & $\begin{array}{l}\text { Cement } \\
\text { Production } \\
\text { (Billion ton) } \\
(\mathbf{2 0 1 5} \text { ton } \\
\text { CEMBUREAU) }\end{array}$ & $\begin{array}{l}\text { \%o } \\
\text { Share } \\
\text { of } \\
\text { total }\end{array}$ \\
\hline China & 0.8038 & 49.6 & 2.5 & 51.3 \\
\hline India & 0.896 & 5.5 & 0.280 & 5.9 \\
\hline Japan & 0.1052 & 6.5 & 0.058 & 1.3 \\
\hline USA & 0.0788 & 4.9 & 0.083 & 1.8 \\
\hline EU & 0.1661 & 10.2 & 0.170 & 5.3 \\
\hline Indonesia & - & - & 0.060 & 1.35 \\
\hline World & 1.6211 & 100 & 4.6 & 100 \\
\hline
\end{tabular}

The annual production of crude steel has been increasingly growing since 2006. A 30\% increase was recorded for worldwide production and almost doubled for China from 2006 to 2014. Around 3\% drop in the world annual steel production was noticed as compared to 2014 according to world steel association.

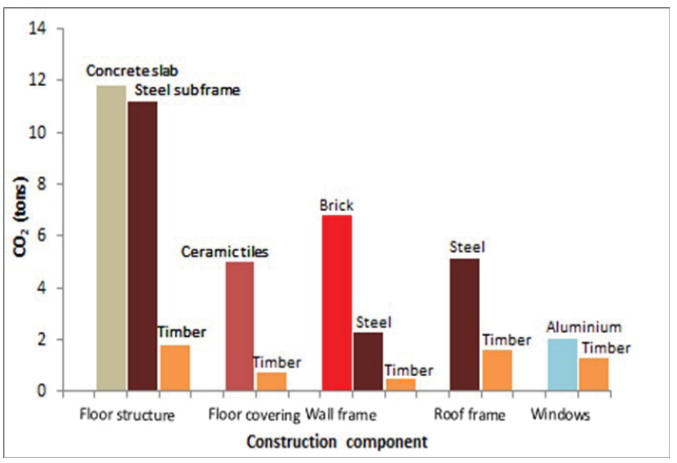

Fig.3. Greenhouse gas emission from the manufacturing of different building components in a family home [8] 
Presently, energy efficiency concept is adopted to reduce operational energy requirements in the construction industry sector by selecting the suitable design and also using insulating materials. Reducing the global $\mathrm{CO}_{2}$ emissions could be achieved also by selecting more sustainable materials that have lower environmental impact. Fig.4 showed that plastic, metal and even glass are generally requiring high embodied energy as compared to other materials such as concrete. However, the large amount of concrete used in construction sector makes it the largest consumed of energy among all construction materials. Extensive efforts are now made not only to design and operate buildings with less energy consumption but also considering other sustainability parameters. An estimated amount of energy of around $40 \%$ is used in Europe for activities related to the construction industry sector.

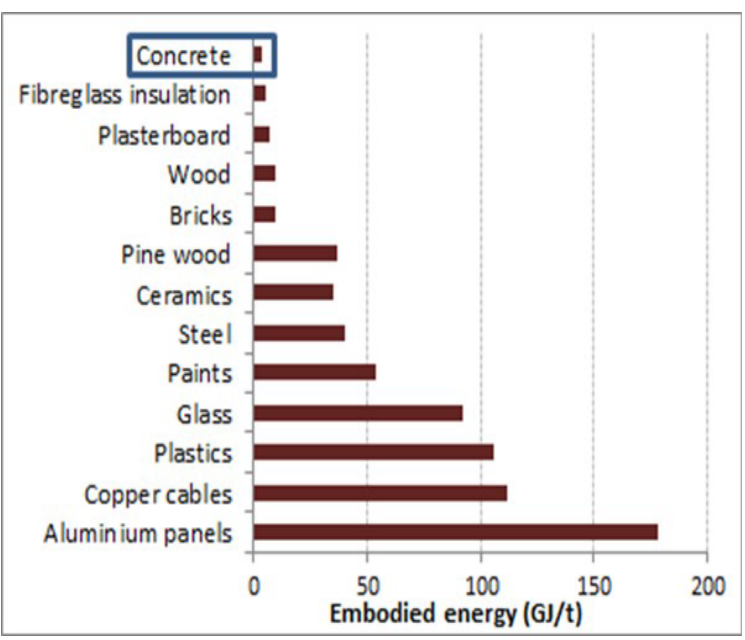

Fig.4. Comparison of embodied energy of construction materials per ton of product [9]

One of the construction industry sectors that consume a large amount of materials (aggregates) and energy is road construction.

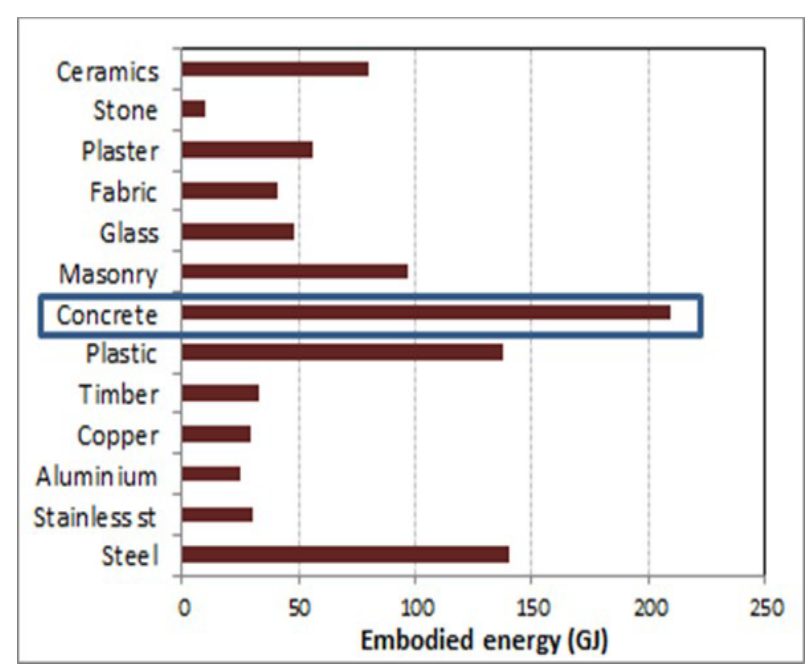

Fig.5. Embodied energy of construction materials based on their use in building [10]

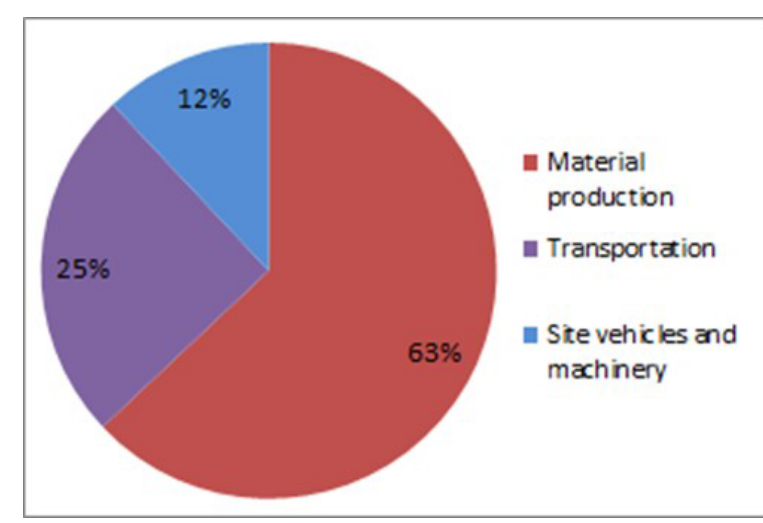

Fig.6. Relative contributions of $\mathrm{CO}_{2}$ emissions in building roadways [11]

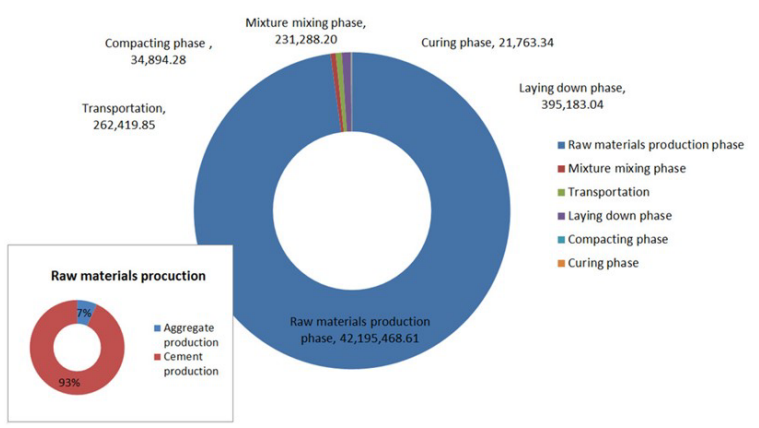

Fig.7. Greenhouse gas emission from Asphalt pavement construction in China [12]

\section{Towards a sustainable concrete construction}

For any socioeconomic development, buildings and infrastructures play a very important role. While developing new buildings and infrastructures has a positive effect on socioeconomic activities and grow, but also it has a significant negative impact on environment and natural resources depletion. The question, what progress and efforts have been undertaken to rationalize the use of natural resources and energy in construction industry? Still this sector is relying and consuming a very large amount of concrete, steel and wood as the three main building materials. As abovementioned, cement and concrete are the main construction materials worldwide used. Cement production has now reached more than 4.6 billion tons which is a double of its production in 2004 (2.11 billion tons). China alone accounts for $51.3 \%$, India $5.9 \%$, Japan $1.3 \%$, and the other Asian countries account for $21.7 \%$. This means that Asia actually produces more than $80 \%$ of the world's cement and also releases the $80 \%$ of the $\mathrm{CO}_{2}$ generated by Portland cement production. In addition, construction as whole has been recognized to consume around $50 \%$ of existing raw materials and $40 \%$ of total energy but also creating $50 \%$ of total solid waste [13].

Given the rate of growth and need for new infrastructures in Asian developing countries and around the world, a direct reduction in world cement production would be difficult to achieved in the near future. 
Therefore, it is necessary to reduce environmental impact by using current technology and practices as efficiently as possible and implementing some good habits in construction. Several recommendations have been made [Sakai, India] to reduce the environmental load of construction without reducing the cement production such as:

1. Lower $\mathrm{CO}_{2}$ emissions levels in cement production to the level of developed countries.

2. Optimize the use of fly ash, blast furnace slag and other pozzolanic materials as replacements for cement.

3. Use a high-range water-reducing agent to reduce the amount of cement used.

4. Reduce the energy consumption required through improvement of construction efficiency.

5. Introduce high-performance concrete with high strength and durability to boost the strength of structural members, thereby reducing their size

6. Introduce technology to minimize energy consumption during the life cycle of a building.

7. Introduce ultra-high strength concrete to promote more advanced structural styles.

8. Use $\mathrm{CO}_{2}$-absorbing concrete.

9. Implement optimal maintenance of buildings.

To produce concrete, with all its different types and performances, and even with considering the above measures, the use of aggregates (coarse and/or fine) in concrete production is indispensable.

For a long time and till now, virgin aggregates commonly called gravel is the main aggregate used to make concrete. Crushed aggregates are also using virgin rocks broken into fragments to obtain aggregates with different sizes. The extraction of these virgin natural resources and crushing them in quarries to produce aggregates is hugely damaging the environment by depletion of natural resources, changing the eco-system and releasing large amount of dusts and fine particles to the atmosphere.

It is recognized that huge quantity of solid wastes is generated annually as a results of demolishing old roads, buildings and infrastructures. Mostly, the concrete debris removed is often considered worthless and would be disposed in landfill. Since many decades ago, there has been attempts to collect the debris of old concrete resulted from demolition of buildings and subject it to a crushing and screening process, quite similarly to the normal aggregate, recycled concrete aggregate (RCA) is produced. The use of RCA to produce concrete for construction industry is not really a new technique but it date back to the after World War II, when there was, on the one hand, accumulation of large amount of waste generated by the excessive demolition of buildings and, on the other hand, an immense need to build new infrastructures and roads [12]. Since that time, several research work have been undertaken to assess the efficiency of using different types of recycled aggregates, including RCA as a partial or even a full replacement of natural aggregate in both structural and non-structural concrete applications. If the main reasons to use RCA in the era of post-World War II was shortage of raw materials and disposing the construction waste accumulated; the motivation now is mainly to make concrete more green and environmentally friendly material.

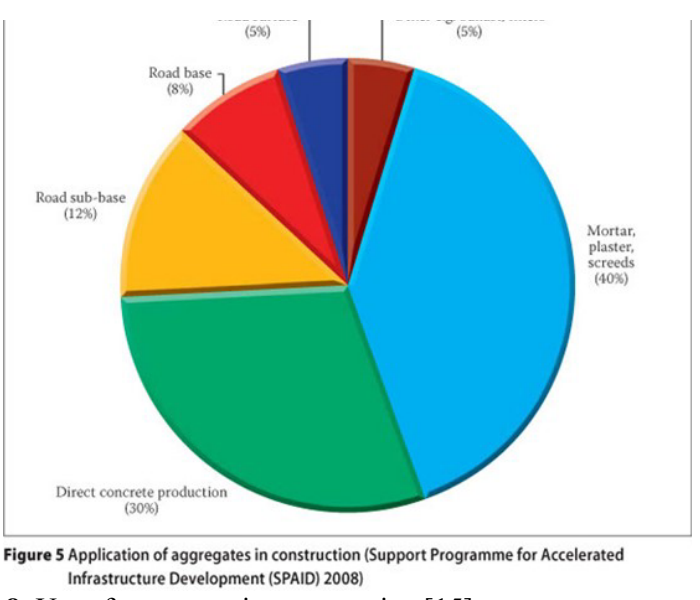

Fig.8. Use of aggregate in construction [15]

Whilst aggregate constitutes the largest component of concrete in terms of volume and lowest in terms of greenhouse gas emission as compared to cement, still its environmental impact is considerable. The environmental impact of a given material is not considered from the point of view of its greenhouse gas emission only but other types of related damages are also counted.

The main objective of this paper is to clarifying the current situation and issues of concrete production on sustainability, and proposes various uses of recycled aggregate for enhancing sustainability in construction. Furthermore, sustainable concrete construction technologies and systems are outlined, with respect to how the concrete sector, which uses a particularly large amount of material, especially aggregates in the construction industry, can contribute, and future design framework for concrete structures, by which we can promote their application, are given.

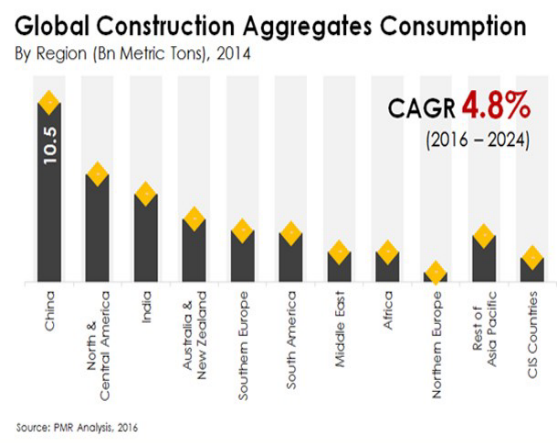

Fig.9. Global construction-aggregates-consumption-market [16]

Aggregates are the world's most mined materials. The global market aggregate market is expected to expand by around 6\% and may reach US\$468.2 billion by 2021 . The world construction aggregate demand for 2015 was estimated at 48.3 billion metric tons[16]. This 
represents 10 times the production of cement and 30 times the production of crude steel.

\section{Aggregates (coarse and fine)}

Aggregates, both coarse and fine, are known to account for an average of around $70 \%$ of the total volume of concrete mixture. Large variety of aggregates sources are available including quarries, alluvial such as gravel and river sands, or recycled aggregates from different industrial waste materials mainly construction and demolition wastes. Currently and in most countries, aggregates from non-processed natural virgin resources such as gravel and sand pits or crushed rocks from quarries, constitute the main sources for raw materials and aggregates used in concrete production.

Although recycled aggregates from different sources are being used but in limited applications such as subbase and base for pavement construction and nonstructural applications still the proper use of recycled aggregate has a great potential to enhance the environmentally friendly aspect of concrete and promote concrete sustainability. The major difficulties that limit the use of recycled aggregate is the recycling facilities and equipment which requires a large investment, especially for high to medium quality of recycled aggregates. Recycled aggregates produced in recycling plants are also subjected to large variety in terms of their quality, especially if they are collected from different sources and sites. Also, standards and codes are still very conservative when it comes to use recycled aggregate in structural applications that requires certain level of durability and engineering properties. Several national standards have already included requirements in terms of using recycled aggregate for design of concrete structures (BS 8500-2, etc.).

\subsection{Embodied $\mathrm{CO}_{2}$ emissions from aggregates}

Data on the embodied $\mathrm{CO}_{2}$ emissions generated by the production of both natural fine and coarse aggregates are not readily available. The InEnergy report published in 2010 estimates that the production of one of ton aggregate including extraction and processing, generates in average $8.1 \mathrm{~kg}$ of $\mathrm{CO}_{2}$ (Table 2).

Table 2. $\mathrm{Co}_{2}$ emissions per ton of aggregate produced [17]

\begin{tabular}{|c|c|c|c|c|}
\hline Activity & $\begin{array}{l}\begin{array}{l}\text { Energy } \\
\text { source }\end{array} \\
\end{array}$ & $\begin{array}{l}\text { Energy } \\
\text { MJ/ton }\end{array}$ & $\begin{array}{l}\mathrm{Kg} \\
\mathrm{CO}_{2} \mathrm{e} / \mathrm{MJ} \\
\end{array}$ & $\begin{array}{l}\mathrm{Kg} \\
\mathrm{CO}_{2} \mathrm{e} / \text { ton } \\
\end{array}$ \\
\hline Quarrying & $\mathrm{ANFO}^{\mathrm{c}}$ & $0.045^{\mathrm{a}}$ & 0.044 & 0.002 \\
\hline $\begin{array}{l}\text { Onsite } \\
\text { transportation }\end{array}$ & Diesel & $26.41^{\mathrm{a}}$ & 0.073 & 1.928 \\
\hline $\begin{array}{l}\text { Crushing, sieving } \\
\text { \& sorting }\end{array}$ & Electricity & 28.80 & 0.119 & 3.43 \\
\hline $\begin{array}{l}\text { Transportation to } \\
\text { construction site } \\
(50 \mathrm{~km})\end{array}$ & Diesel & 38 & 0.073 & 2.774 \\
\hline Total & & 93.3 & 0.309 & 8.1 \\
\hline \multicolumn{5}{|c|}{$\begin{array}{l}\text { a. Based on the assumption that diesel oil constitutes } 99.9 \% \text { of the energy and } \\
\text { explosives are } 0.1 \% \text { during quarrying. } \\
\text { b. Typical transportation distances of materials to site; the capacity of the truck is } \\
\text { estimated to be } 25 \text { t for aggregate. } \\
\text { c. ANFO - Ammonium Nitrate Fuel Oil } \\
\text { Note: The } \mathrm{CO}_{2} \text {-e data on the cradle-to-gate phase of concrete constituents and } \\
\text { concrete products. }\end{array}$} \\
\hline
\end{tabular}

\subsection{Recycled aggregate}

Properties of aggregate used to produce concrete are known to exercise a significant effect on the concrete performance. Recycled aggregates are available in large variety depending on local industries and materials used.

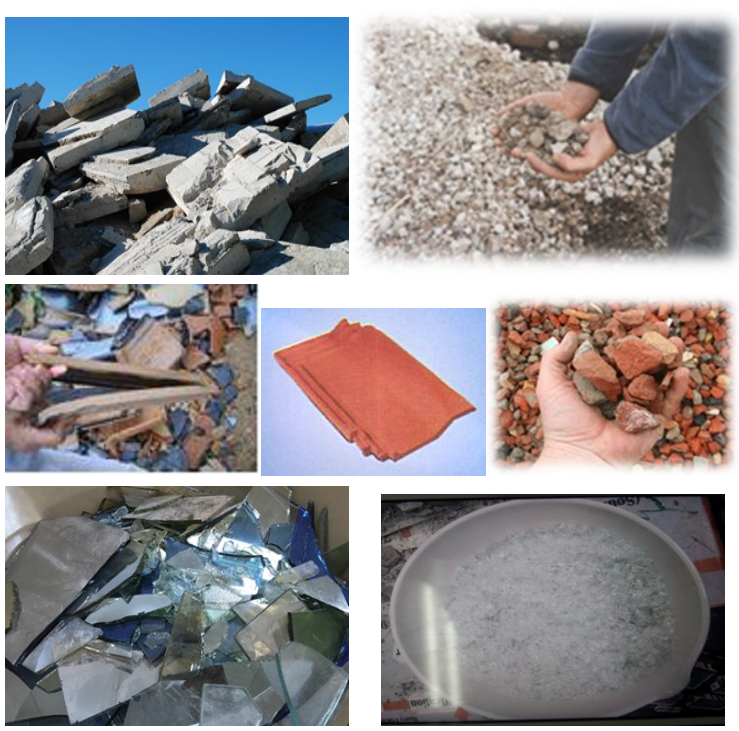

Fig.10. Recycled aggregates issued from various types of construction wastes

Recycled concrete aggregate, however, are the most abundant due to availability of their source and continuous demolishing of old buildings and pavements. Fig. 10 illustrates some types of recycled aggregates, and their sources, that have been employed in this study. The physical and mechanical properties of recycled aggregate are the main factor limiting the use of recycled aggregate in concrete. Lower properties are mostly resulting from using recycled aggregate as compared to their corresponding natural aggregates. Table III summarizes the main properties of three different types of recycled aggregates, namely recycled concrete aggregate (RCA), Porous ceramic aggregate (PCA) and Recycled crushed waste glass (RCG).

Table 3. Materials properties

\begin{tabular}{|c|c|c|}
\hline Materials & Type & Properties \\
\hline Cement & $\begin{array}{l}\text { Normal Portland } \\
\text { Cement }\end{array}$ & $\begin{array}{l}\text { Specific gravity: } 3.16 \\
\text { Surface area: } 3260 \mathrm{~cm}^{2} / \mathrm{g}\end{array}$ \\
\hline \multirow[t]{2}{*}{$\begin{array}{l}\text { Chemical } \\
\text { admixtures }\end{array}$} & $\begin{array}{l}\text { Water reducing } \\
\text { agent }\end{array}$ & Lignosulphonate Polymer \\
\hline & $\begin{array}{l}\text { High range water } \\
\text { reducing agent }\end{array}$ & Polynaphtalene sulphonate \\
\hline $\begin{array}{l}\text { Recycled coarse } \\
\text { aggregates }\end{array}$ & $\begin{array}{l}\text { Recycled concrete } \\
\text { aggregate }\end{array}$ & $\begin{array}{l}\text { Specific gravity: } 2.43 \\
\text { Water absorption: } 5.3 \% \\
\text { Crush rate: } 23.4 \% \\
\text { Aggregate size: } 5-20 \mathrm{~mm}\end{array}$ \\
\hline $\begin{array}{l}\text { Recycled fine } \\
\text { aggregates }\end{array}$ & $\begin{array}{l}\text { Recycled waste } \\
\text { glass aggregate }\end{array}$ & $\begin{array}{l}\text { Specific gravity: } 2.49 \\
\text { Water absorption: } 0.06 \% \\
\text { Aggregate size: } 0-5 \mathrm{~mm}\end{array}$ \\
\hline
\end{tabular}




\subsection{Concrete design and testing procedures}

As given in Table I, three types of recycled aggregates (two coarse and one fine) were included in this study. Several concrete mixtures with various water-to-cementratio $(\mathrm{w} / \mathrm{c})$ were designed to elucidate the effect of types and properties of recycled aggregate used on concrete performances. For this study, compressive strength was measured on both cubic samples of $100 \times 100 \times 100 \mathrm{~mm}$ and cylindrical ones of $100 \times 200 \mathrm{~mm}$. Splitting tensile strength was measured on cylindrical specimens of $150 \times$ $300 \mathrm{~mm}$. Both compressive and splitting tensile strength tests were carried out at 28 days of curing in water at 20 $\pm 2{ }^{\circ} \mathrm{C}$.

\section{Recycled aggregate concrete performances}

\subsection{Strength performances}

Tensile, and especially compressive strength of concrete are the two main mechanical performances required for structural design of concrete structures. The 28-day compressive and splitting tensile strengths are given in Fig. 11.

As could be seen in Fig. 11 (a) and (b), the partial or full replacement of natural coarse or fine aggregates by recycled aggregate lead to a strength reduction regardless of the type of recycled aggregate and their replacement level. The higher the replacement level of natural aggregate by recycled one, the largest the reduction in strength. This strength reduction is strongly affected by the recycled aggregate properties, their production process and the primary material from which they were recycled.

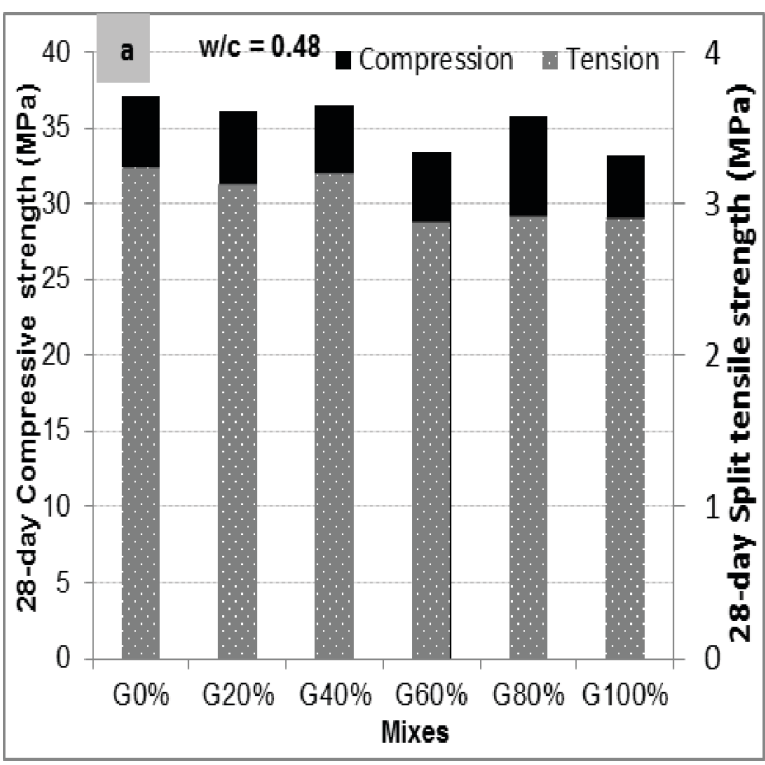

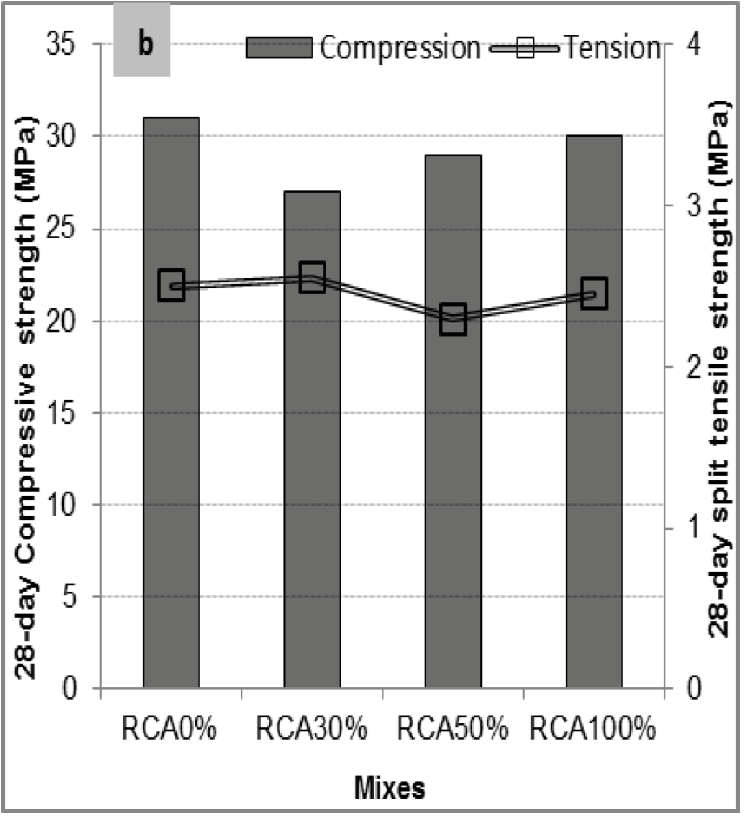

Fig.11. Effect of recycled glass fine aggregate (a) and recycled concrete coarse aggregate (b) on the 28-day compressive and tensile strengths of concrete

\subsection{Durability performances}

Durability performances of concrete can be evaluated by various tests and experiments. The most common tests used to assess the durability are resistance to aggressive attack such as chloride, sulfate or acids. Also, shrinkage (autogenous and drying) is one of the serious issues related to durability of concrete structures because an excessive shrinkage may lead to cracking of concrete. Cracks in concrete may lower the load carrying capacity of the structure and are also the major factor allowing penetration of harmful materials such as sulfate, chloride ions, carbon dioxide and acids.

Generally, it has been found that the partial replacement of natural aggregate by RCA could increase the drying shrinkage of concrete. The full replacement, however, of NA by the RCA may have substantially increase the total magnitude of drying shrinkage strains of concrete up to double even more as shown in Fig.12. This significant increase of shrinkage strains in concrete designed with RCA is completely attributed to the adhered old mortar on the RCA. One of the remedies proposed to overcome this excessive shrinkage strains is to reduce the volume of mortar and increase the portion of solid aggregate in concrete made with RCA.

Furthermore, total porosity and pore size distribution is one of the major factor affecting durability performances of concrete. Porosity is highly affected by numerous parameters related to both the cement matrix and the aggregates skeleton. With the same cement matrix characteristics, using recycled aggregates in partial/full replacement tends to increase the porosity of the resulting concrete. This effect is obviously function of the aggregates properties. Most RCA increase the total volume of pores due to the high porosity of the adhered mortar on RCA. 

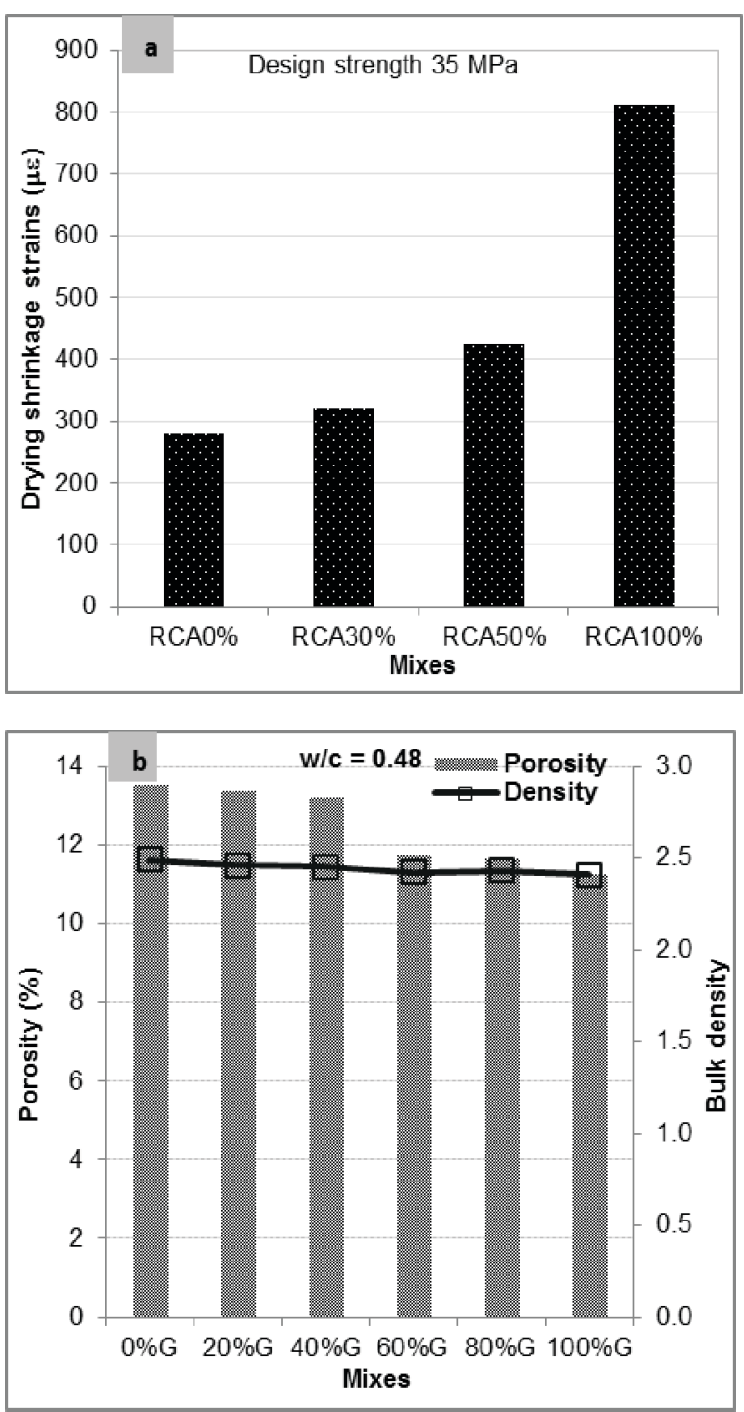

Fig.12. Effect of recycled concrete coarse aggregate on drying shrinkage (a) and waste glass fine aggregate on porosity (b) of concrete

\section{Concluding remarks}

Over the past few years, sustainable development and sustainability have emerged as the latest human innovation and become the motto of today's environmental protection. The concept of sustainability is now found everywhere and has been introduced as a pre-requisite for many socioeconomic activities. Construction industry has been recognized not only as one of the major contributors to energy and natural resources consumption but also as responsible of releasing a significant portion of the global carbon dioxide. The process of extracting, processing and manufacturing construction materials is causing damages to the environment. The process of manufacturing Portland cement alone is said to contribute to approximately $7 \%$ of the total $\mathrm{CO}_{2}$ emissions. In addition to other related construction activities.
Reducing clinker production and Portland cement consumption has been under the spot for a long time. Several genuine composite cements and pozzolanic/cementitious materials are now being developed and largely used in various concrete types and construction applications to reduce Portland cement consumption and hence, $\mathrm{CO} 2$ emissions.

Apart from cement, aggregate accounts for $65-80 \%$ of the total volume of concrete and could significantly affect the environmental load of concrete and its level of sustainability. Aggregates for concrete are whether collected as gravel or produced as a result of crushing rocks. In both cases, the excessive use of natural aggregate to respond to the high demand of construction leads to depletion of non-renewable resources. Introducing secondary aggregate from different sources such as aggregates collected from demolished buildings and subjected crushing and screening and then used in new concrete production has many environmental advantages. The experimental data available showed that properties of concrete made with RCA is depending on the properties of the RCA and the parent concrete from where they have been crushed. This concrete needs a special care and proper design parameters to obtain a nearly comparable performances to those made with natural aggregate. Overall, a moderate replacement content of around $30 \%$ should not be exceeded to avoid major negative effect of RCA on the new concrete properties. Other types of recycled aggregate have also proven to have less negative impact on strength and durability related performances such as recycled glass, and especially porous ceramic aggregate. Promoting the use of various types and contents of recycled aggregates in modern concrete may significantly reduce the amount of solid waste being disposed, safeguarding natural nonrenewable resources and overall enhancing sustainability in construction industry sector.

\section{References}

1. British Petroleum (BP), Statistical review of world energy,

2. IPCC, Climate change, Syntheses report (2014).

3. National Oceanic and Atmospheric/Earth System Research Laboratory (NOAA/ESRL 2015), Trends in atmospheric carbon dioxide.

4. T. A. Boden, G. Marland, R. J. Andres. Carbon Dioxide Information Analysis Center, Oak Ridge National Laboratory, U.S. Department of Energy (2015). .

5. United States Geological Survey. USGS Mineral Program Cement Report, 44-45 (2015)

6. CEMBUREAU 2011. Available at: http://www.cembureau.be/

7. K. Sakai. Proceedings of the International UKIERI Concrete Congress Concrete Research Driving Profit and Sustainabilityp held at Dr Ambedkar National Institute of Technology Jalandhar, Punjab, India, on 2 - 5 November 2015pp. 3-17.

8. Cooperative Research Centre for Greenhouse Accounting, Report (2006).

9. H. Kara. Sustainable Construction Materials, Envirocities eMagazine, 10 29-32 (2015)

10. CSIRO Commonwealth Scientific and Industrial Research Organisation, Report (2015). 
11. RoadReady Newsletter, Pavement interactive, Newsletter (2012).

12. F. Ma, A. Sha, R. Lin, Y. Huang, C. Wang. International Journal of Environmental Research and Public Health, 13 351(2016)

13. N. Oikonomou. Recycled concrete aggregates, Cement \& Concrete Composites, 27 315-318 (2005)

14. D. Buck. Recycled concrete as a source of aggregate, ACI Journal, 74 (1977) 212-219 (2005)

15. SPAID (Support Programme for Accelerated Infrastructure Development) 2008. Research Report for the Infrastructure Inputs Monitoring Strategy. Available at http://www.spaid.co.za/downloads/

16. Aggregates market accessed at https://www.pinterest .com/lehighhanson/aggregates/

17. World Energy Report 2010, International Energy Agency, https://www.iea.org/publications/freepublication s/publication/weo-2010.html 